\title{
An inexpensive contact angle measurement system
}

\author{
Musa Faruk Çakır \\ Çankırı Karatekin University, Electronics and Automation Department, \\ Çankırı, Turkey. \\ *e-mail: mcakir@karatekin.edu.tr
}

Received 9 June 2021; accepted 30 July 2021

\begin{abstract}
In this study, a new and cost-effective contact angle measurement system has been developed. As direct application of this easy-to-use measuring system, the wettability behavior of acrylic polymers was analyzed by dropping a saline solution of $2.4 \mathrm{M}$ on acrylic materials, where contact angle measurements were made.
\end{abstract}

Keywords: Contact angle measurement system; contact angle; wettability; acrylic.

DOI: https://doi.org/10.31349/RevMexFis.68.021001

\section{Introduction}

The wettability phenomenon is the act of spreading a liquid over a solid material and is characterized by measuring the angle formed between both substances, which is called the contact angle (CA) [1]. According to the values of the contact angle, if the liquid is water, the wetted material can be divided into groups of materials that are called super-hydrophilic or super-hydrophobic. If the degree of the contact angle is above $160^{\circ}$ degrees, it is considered super-hydrophobic, and superhydrophilic, if less than $20^{\circ}$. While super-hydrophobic materials have a high aversion to oil, they have the potential to serve the purpose of oil/water separation layers as they remove water completely $[2,3]$.

Contact angle measurement systems are needed to determine the wettability behavior of materials. However, contact angle measurement systems are expensive and very complex to use. In addition, special training is needed for their use. Periodic maintenance and upgrade fees of such systems are also quite high. In this study, in order to perform contact angle measurements, a contact angle measurement system that is easy to use and can be used in multidisciplinary studies has been designed. Developing the software of the measurement system, which is carried out at a low cost, according to the existing systems and integration with other analysis software is one of its most important advantages. In addition, the fact that it is open to innovations and development in terms of software and hardware makes the contact angle measurement system more prominent than other measurement systems.

The wettability behavior of acrylic materials with salt water was investigated in order to apply with the performed contact angle measurement system. The use of acrylics, which are required for the production of polymers, are quite wide [4]. Acrylic has been extensively studied by researchers for its excellent properties such as high electrical resistance, good thermo-stability, lightness and good workability [5]. These properties have led to the increasing use of acrylics in various fields such as filtration, air purification and rechargeable batteries. Acrylic is used in the cleaning industry due to its antimicrobial properties as well as being a polymer-structured and hygienic material [6,7]. Multifunctional acrylic materials are increasingly becoming more popular in academic and industrial studies due to the manufacture of super-hydrophobic films and coatings, liquid repellence and other properties such as electrical conductivity [8,9], magnetic activity [10], high-voltage applications [11], transparency [12], strong substrate adhesion [13], mechanical rigidity [14,15], frost prevention [16] and self-healing [17] have increased the interest in these materials. By determining the contact angle in acrylic materials, they are directed to many application areas.

\section{Contact Angle and Wettability Behavior}

\subsection{Contact angle}

The contact angle is critical in determining the wettability behavior. This angle is determined by measuring the angle formed between the liquid and the solid material. However, the effect of the ambient air and gravity on this angle should also be remembered. In fact, the contact angle can also be defined as the angle formed by the materials in solid, liquid and gas phases with the effect of gravity. The magnitude of this angle depends on the relative size of the attraction forces (cohesion forces) between the liquid's own molecules and the attraction forces (adhesion forces) between the liquid and the solid. The greater the magnitude of the cohesion forces than the adhesion forces, the greater the contact angle between the liquid and the solid. In other words, a large contact angle indicates that the liquid-solid gravitational forces are low, and a small contact angle indicates that these forces are large. Methods such as the half-angle, tangential, Young-Laplace, ellipse, and polynomial methods are used in the calculation of contact angles [18]. In this study, the half-angle method was used in the measurement of the contact angle of the acrylic 


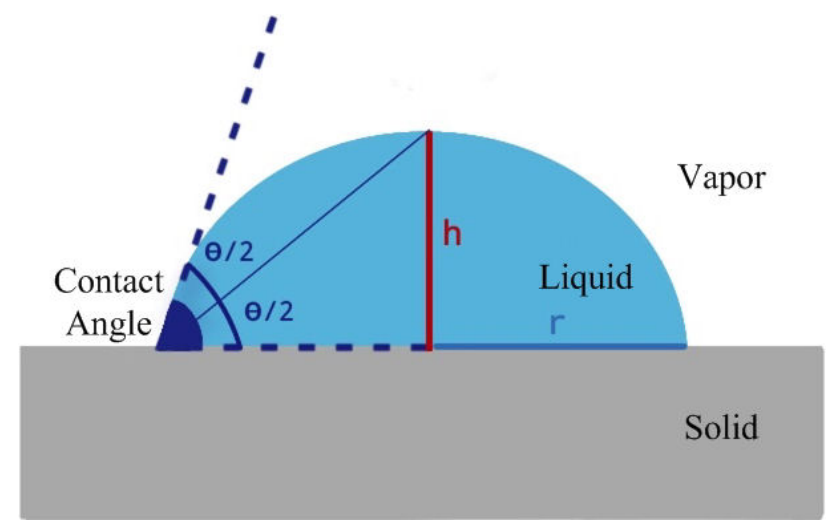

FIGURE 1. Schematic representation of contact angle measurement using the $\theta / 2$ method.

materials. The half-angle method considers that the drop on the solid surface is part of an ideal sphere and its cross-section is a circle. When the vertical height formed by the drop on the solid surface is taken as $h$ and the base radius of the drop as $r$, the contact angle can be calculated as shown in Eq. (1) $[19,20]$. In Fig. 1, a schematic representation of the measurement of the contact angle using the half-angle method is presented.

$$
\Theta=2 \tan ^{-1}\left(\frac{h}{r}\right) .
$$

Today, many contact angle approaches [21,22] have been heavily inspired by Young's equation for determining surface energy. Although these approaches differ logically and conceptually, they share some basic assumptions. All of these approaches are based on the validity of Young's experimental surface energy and contact angle equation. Some of these studies suggested that pure liquids should always be used, but active ingredient solutions or liquid mixtures should not be used as they would cause complications. In these studies, the authors stated that care should be taken to avoid physical or chemical reactions between the wet solid surface and the dropped liquid. They also emphasized the importance of the liquid surface tension of the liquids used being higher than the solid surface tension. The contact angle value is expressed in hysteresis as the time-dependent change of the liquid from the drop on the solid surface. In addition, advancing and receding contact angle values do occur. The contact angle $\theta_{0}$, in terms of the advancing and receding contact angles, $\theta_{A}$ and $\theta_{R}$, respectively, on a completely smooth surface was calculated by Tadmor and shown in Eq. (2) [23].

$$
\theta_{0}=\cos ^{-1}\left(\frac{\Gamma_{A} \cdot \cos \theta_{A}+\Gamma_{R} \cdot \cos \theta_{R}}{\Gamma_{A}+\Gamma_{R}}\right),
$$

where $\Gamma_{A}$ and $\Gamma_{B}$ values are expressed as:

$$
\Gamma_{A}=\left(\sqrt[3]{\frac{\sin ^{3} \theta_{A}}{2-3 \cdot \cos \theta_{A}+\cos ^{3} \theta_{A}}}\right),
$$

and

$$
\Gamma_{R}=\left(\sqrt[3]{\frac{\sin ^{3} \theta_{R}}{2-3 \cdot \cos \theta_{R}+\cos ^{3} \theta_{R}}}\right) .
$$

The validity of Young's equation requires solid surfaces to be hard, smooth and homogeneous.

\subsection{Wettability behaviors}

Wettability behavior is a technical term first defined by Young $[24,25]$. The contact angle between the surface of the material and the liquid drop is the most significant factor explaining the wettability behavior of the material. When the liquid drop is dropped onto the material, the molecules in the interior of the liquid draw each other from all directions. On the surface where it is dropped, the energies called surface tension ensure that it continues to maintain its spherical shape.

Surface energy and surface tension are the context of explaining the same phenomena for different physical reasons. It would be more accurate to use the expression surface tension for liquids and surface energy for solids. While the contact angle is being formed, surface tensions are occurring. There are three types: Liquid-Air $\left(\gamma_{L V}\right)$, Solid-Liquid $\left(\gamma_{S L}\right)$ and Solid-Air $\left(\gamma_{S V}\right)$. The contact angle and surface tensions of a drop are shown in Fig. 2.

A relationship between the contact angle and surface tensions is given in Eq. (3). This equation also forms the basis of wettability behavior and takes the name of Young's Equation [25].

$$
\gamma_{S V}=\gamma_{S L}+\gamma_{L V} \cdot \cos \theta
$$

The wettability characteristics of the solid materials emerge based on the value of the contact angle formed with the liquid dropped on the solid material. If the contact angle value is below $90^{\circ}$ the solid material exhibits

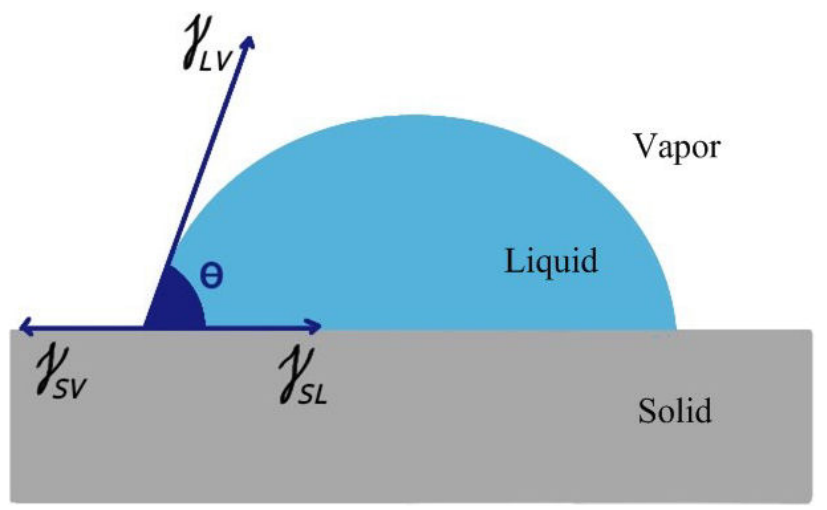

FIGURE 2. Contact angle and surface tensions of the sessile drop. 


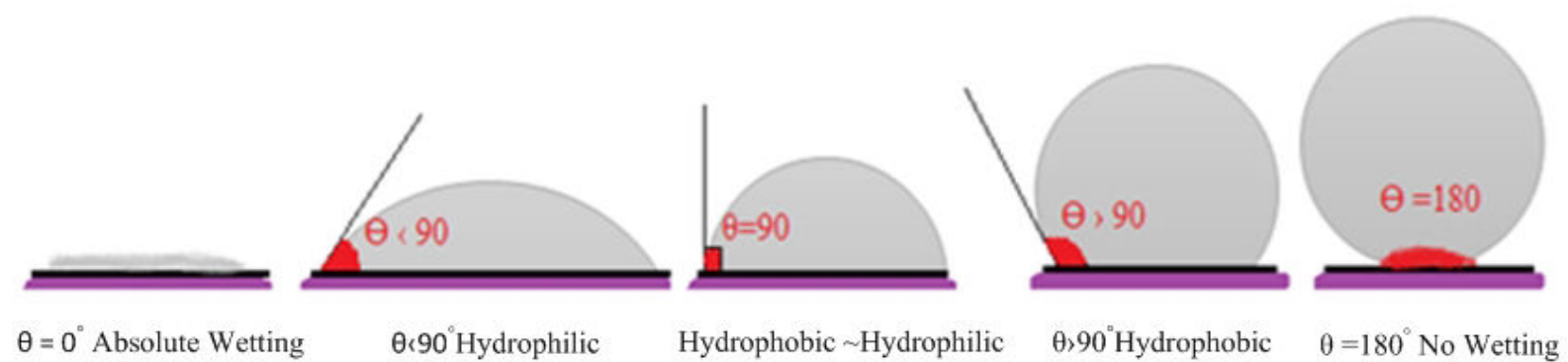

FIGURE 3. The representation of the wetting behavior based on the value of the contact angles.

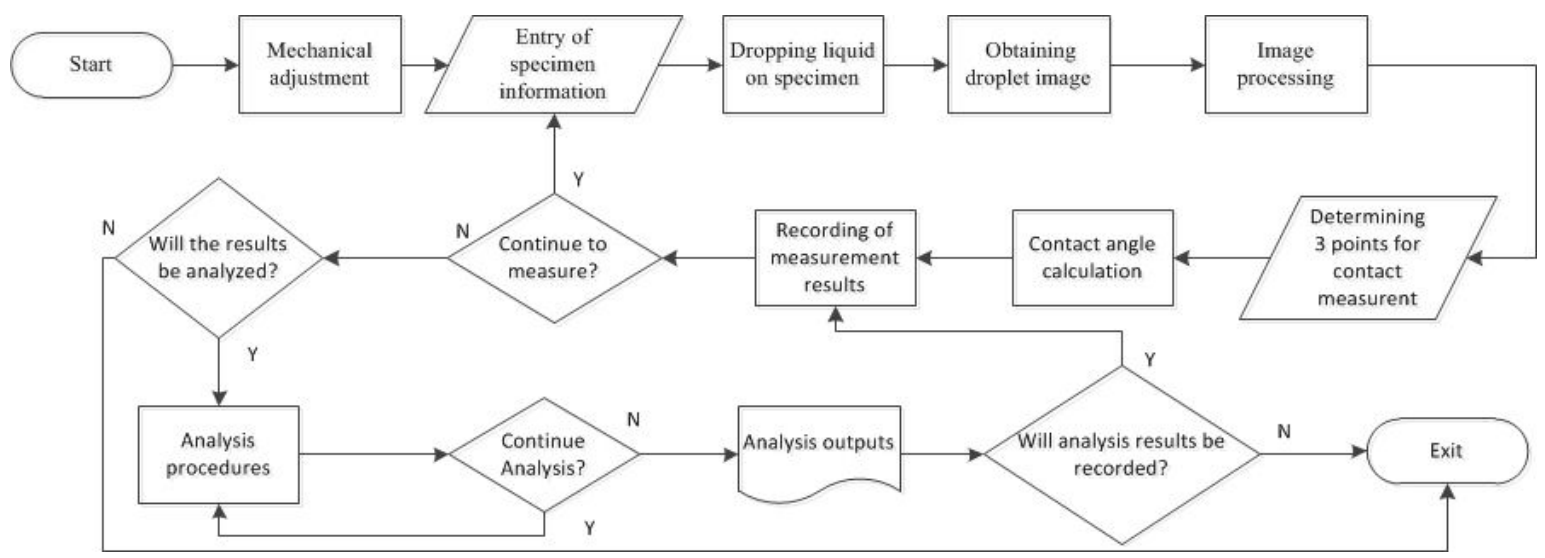

FIGURE 4. Block diagram of the contact angle measuring system.

hydrophilic properties and hydrophobically if it is above $90^{\circ}$ [26]. When the value of the contact angle is exactly zero, there is full wetting and if it is $180^{\circ}$, it is understood that there is no wetting behavior. In Fig. 3, the conditions of the wetting behavior based on the value of the contact angles are shown.

\section{Contact angle measurements systems}

Systems that make contact angle measurements consist of hardware and software in the market and are sold for around $\$ 5,000-30,000$. In addition, special training is required to use these systems. Due to the high price of the system, we designed and developed a contact angle measurement system within our own facilities. The cost of the designed and implemented system is approximately $\$ 400$. The block diagram of the system is shown in Fig. 4. The operation of the measuring system is clearly explained in blocks.

The measuring system consists of two parts, including software and hardware. The hardware section consists of lighting, a digital microscope, a syringe, a sample placement platform, mechanical apparatus for the distance-height adjustment of the materials and a laptop computer. Specific mechanical parts were manufactured using a 3D printer. It is given in Fig. 5 a schematic representation of the contact angle measuring system. Figure 6 depicts the setup for the system.

The hardware parts of the contact angle measuring system are given below.
1. Digital microscope distance adjustment mechanism.

2. Lighting focus adjustment mechanism.

3. Digital microscope right-left adjustment mechanism.

4. Adjustment mechanism of specimen placing platform.

5. Height adjustment mechanism of syringe.

6. Specimen.

7. Illumination.

8. Syringe.

9. Droplet.

10. Laptop.

11. Digital microscope.

The software section, however, is the section where images of the droplet contact angle taken with the help of a digital microscope are processed using basic image processing techniques and the contact angle values are calculated and the results are reported. The image of the droplet on the sample is taken with a digital microscope and transferred to the computer. Before taking the image, the distance and height settings of the lighting and the digital microscope are adjusted to get the sharpest image. The droplet images taken are examined and the contact angle is cleared from shadows and 


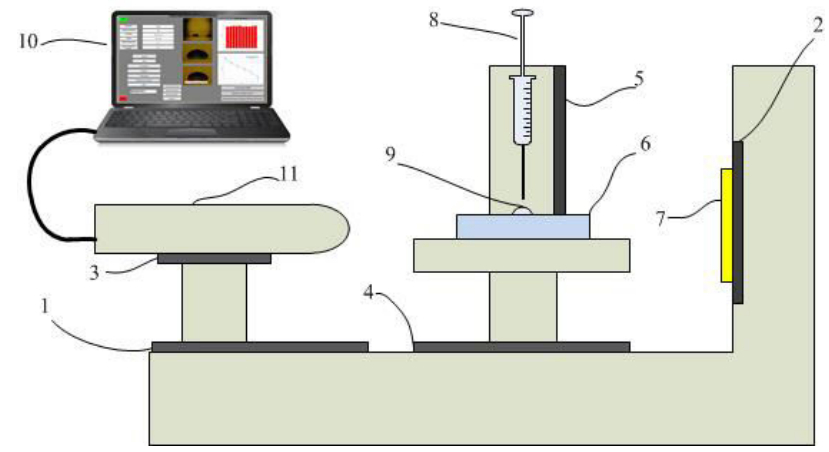

FIGURE 5. Schematic representation of the contact angle measurement system.

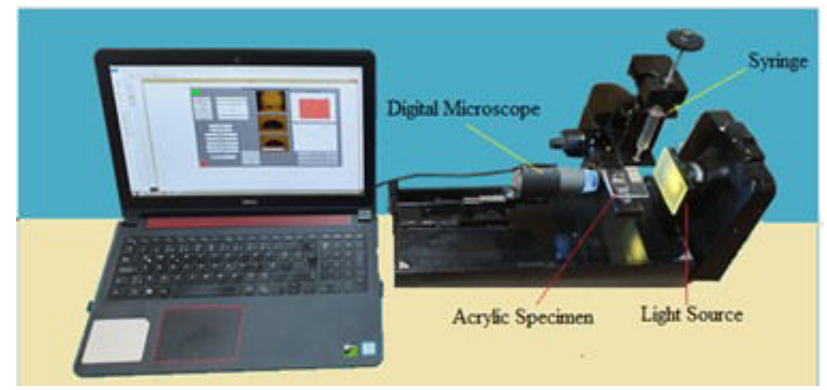

FIGURE 6. Contact angle measurement system.

reflections for proper measurement. Contact angle measurement is performed from the clearest cleared image.

In order to carry out the analysis and presentation of graphical results of measurements, a piece of software was developed. With the software, the contact angle can be analyzed with respect to some parameters (time, distance, droplet volume, droplet height, etc.). Also in this section, there is a user interface created using MATLAB. The control of the contact angle measurement system and obtaining the analysis data was carried out through the interface created. The user interface of the contact angle measurement system is presented in Fig. 7. The system was created in a flexible way to enable being used in all multidisciplinary studies. In addition, it has an ergonomic design that can be used easily in chemistry, physics and materials laboratories.

It is easier to use than other measuring systems. There is no need for a special training. Most measurement systems do not have features such as analysis and graphing. In the measurement system we have implemented, program addition and deletion operations can be performed if desired. This feature reveals the ability of such systems to modernize themselves when needs and purposes change. Otherwise, the system will not be used for many years.

\subsection{Preparation of acrylic samples and performing con- tact angle measurements}

Acrylic samples to be measured contact angle were prepared in the dimensions of $5 \times 25 \times 40 \mathrm{~mm}^{3}$. A $2.4 \mathrm{M}$ (molarity) saline solution was used to analyse the wettability behavior of acrylic materials with saline ( $\mathrm{NaCl}$ solution). Pure water was used as water when preparing the saline solution. Conductivity values of the solutions produced were measured with the help of SG78 - (SevenGo Duo pro pH/Ion/Conductivity Meter, Mettler Toledo). In this study, 2.4 M saline solution

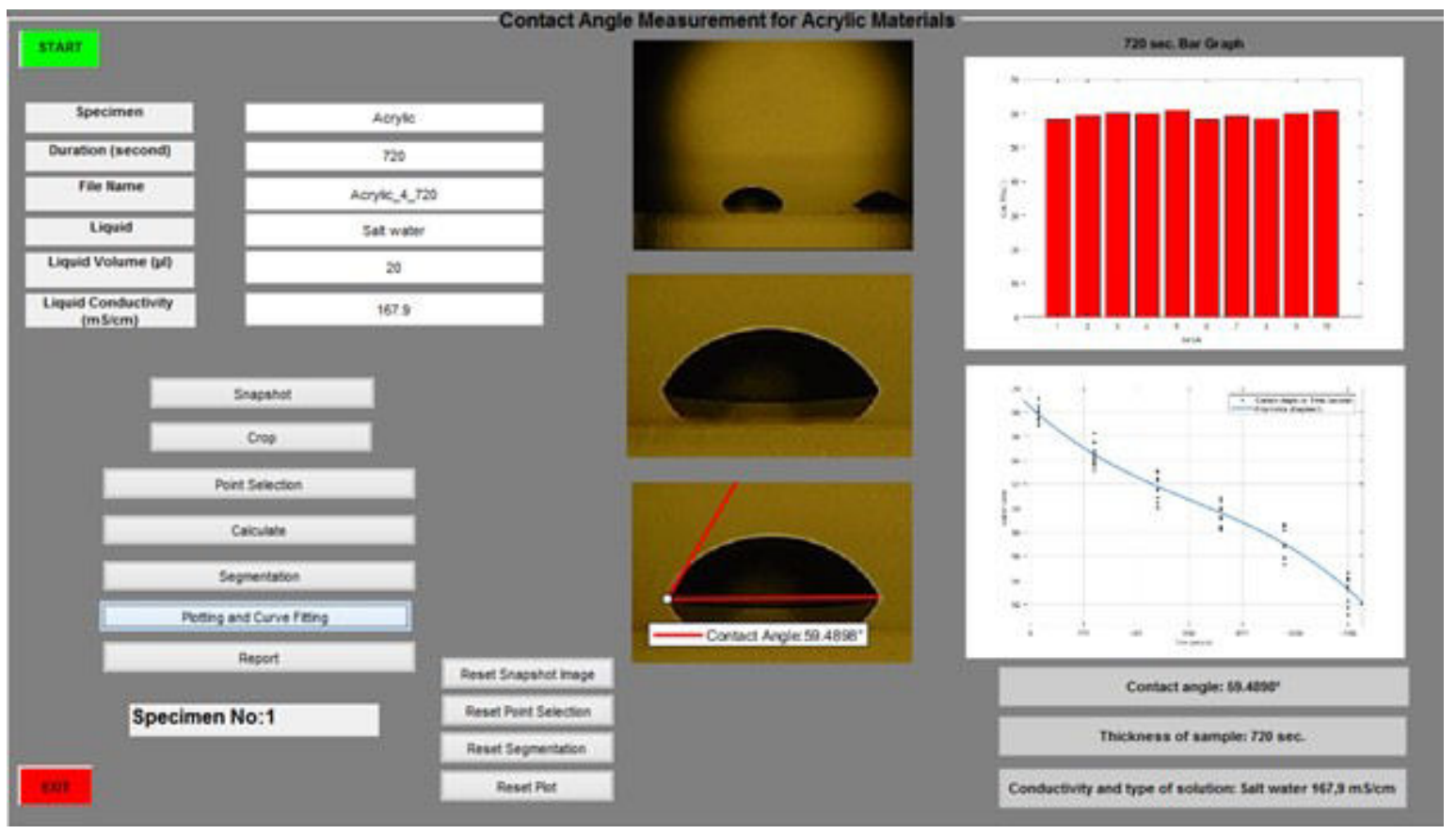

FIGURE 7. User interface view of the contact angle measurement system. 
with conductivity of $167.9 \mathrm{mS} / \mathrm{cm}$ was used as droplet liquid. Surface roughness values of acrylic samples of which contact angles to be measured were measured using a Ra Mitutoyo SJ-410 brand profilemeter. The average surface roughness of the acrylic samples was measured as $R_{a}=0.012 \mu \mathrm{m}$. This value means that the roughness value of the surface of the acrylic sample is very small.

Before measuring contact angle values, the contact surface of the samples must be clean. This was done with 99measurement, as well as rinsed with pure water and dried. Only when the temperature of the sample reached room temperature, it was placed in the measurement system without human touch. A Celestron 44308 digital microscope was used to obtain the contact angle images of the acrylic material and saline solution sample. In the image processing part of the contact angle measurement system, the images taken from the experimental platform with a digital microscope were brought into the form to be measured by using software and image processing techniques prepared in MATLAB. The so-called sessile drop method was used when calculating the contact angle. Reflections and nonsense regions were removed from the droplet images. Following the determination of the baseline, right, left and top end points of droplet on the acrylic surface, the contact angle was calculated using image processing techniques and half-angle method. The half-angle method considers the sessile drop as the half of an ideal sphere. As a result, the contact angle was calculated with the help of this method, based on the height of the drop and the radius of the base.

\section{Experimental results}

With the help of the interface created, images can be taken from the droplet left on the surface at desired time intervals. In the interface system, the image is obtained at any time with the help of a digital microscope after entering information such as the name of the sample, the number of seconds after the droplet is dropped and the drop volume, etc. When the drop image is displayed on the screen, the necessary operations for measurement can be performed by using the buttons for clipping, point selection, calculation and image processing. Three points are determined on the image of the drop and the contact angle is calculated. Reports can also be extracted from the interface system. These images can be analysed using basic image processing techniques. All values measured can be stored in memory and used at any time.

After the acrylic sample was prepared and the necessary cleaning process was performed, it was placed in the contact angle measurement system without human touch. A $2.4 \mathrm{M}$ saline solution was dropped onto the sample in a volume of 20 microliters with the help of a syringe on the system. After 2,4 M saline was dropped on the acrylic sample, contact angle measurements were carried out at $30 \mathrm{~s}, 240 \mathrm{~s}, 480 \mathrm{~s}, 720$ s, $960 \mathrm{~s}$, and $1200 \mathrm{~s}$ intervals. These measurements

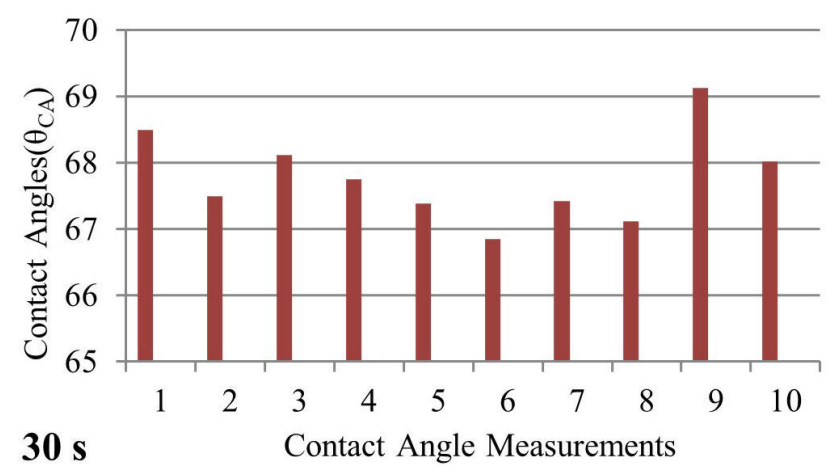

FIGURE 8. The bar graph of contact angle values measured after 30 seconds by dropping 2.4 Molar saline to the acrylic sample.

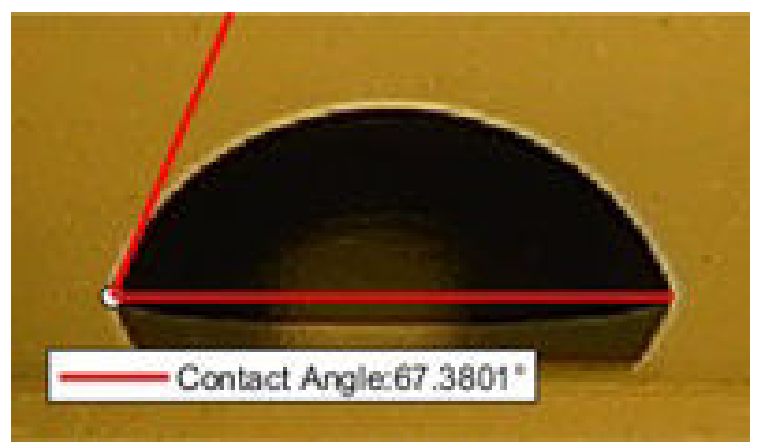

FIGURE 9. Contact angle value (for 30 seconds).

were repeated 10 times for each drop. The graph of the contact angle measurement values made for the waiting period of 30 seconds is shown in Fig. 8.

When 10 different measurements were performed for 30 seconds and averaged, the contact angle value was obtained as $\theta_{C A}(30 \mathrm{~s})=67.3801^{\circ}$. The contact angle for 30 seconds is shown in Fig. 9.

Similarly, bar graphs of contact angle measurement values made for each waiting time were drawn and are shown in Fig. 10.

When the measurements were completed and when the average of the measurements made for each waiting period was taken, the contact angle values given in Table I were achieved.

TABLE I. Contact angles for $30 \mathrm{~s}, 240 \mathrm{~s}, 480 \mathrm{~s}, 720 \mathrm{~s}, 960 \mathrm{~s}$ and $1200 \mathrm{~s}$ waiting times when 20 microliters of $2.4 \mathrm{M}$ saline water is dropped on acrylic material: $t=$ Waiting Time (s), $\theta_{C A}=$ Contact Angle $\left({ }^{\circ}\right)$

\begin{tabular}{cc}
\hline$t$ & $\theta_{C A}$ \\
\hline 30 & $67,3801^{\circ}$ \\
240 & $64,3046^{\circ}$ \\
480 & $61,5683^{\circ}$ \\
720 & $59,8443^{\circ}$ \\
960 & $56,9913^{\circ}$ \\
1200 & $53,4594^{\circ}$ \\
\hline
\end{tabular}



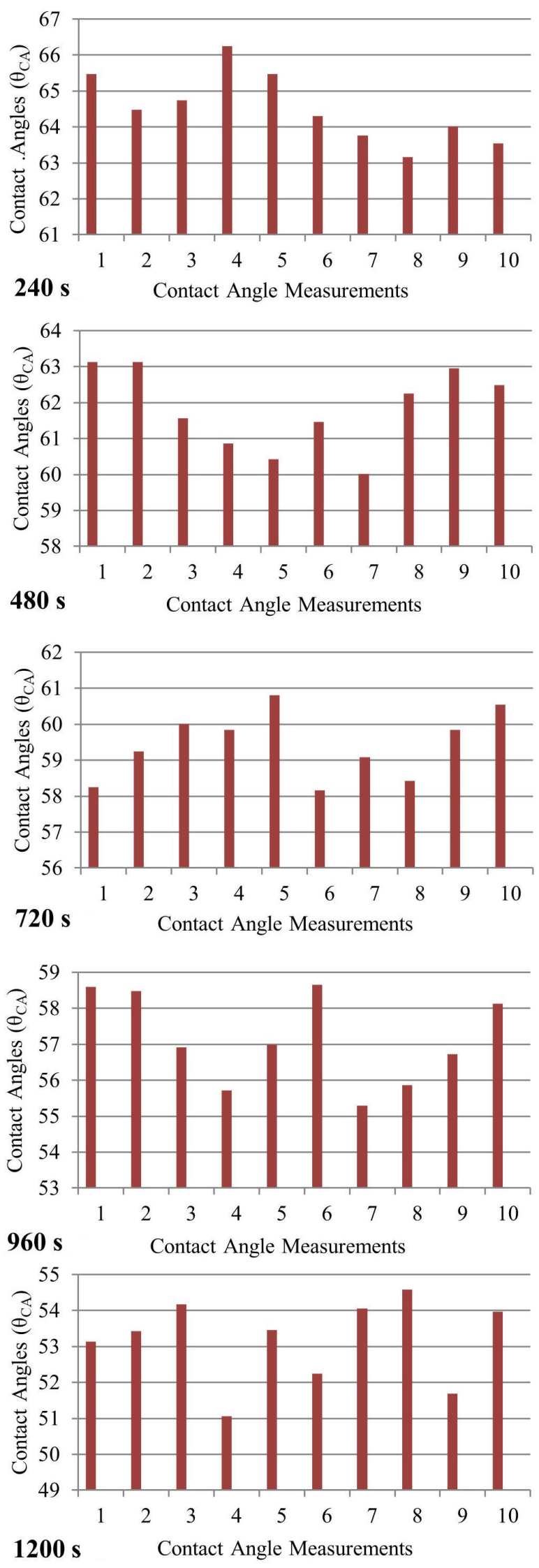

FIGURE 10. Contact angle bar graphs (for 240 s, 480 s, 720 s, 960 $\mathrm{s}$ and $1200 \mathrm{~s}$ ).
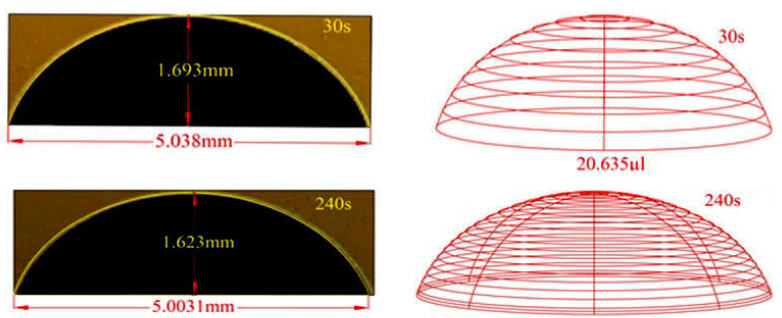

$19.409 \mu \mathrm{I}$
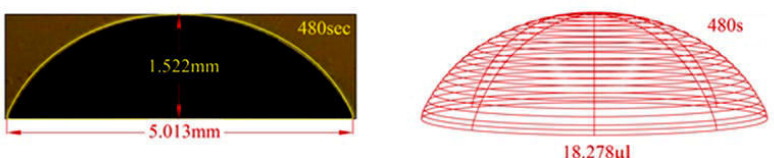

$\mid 8.278 \mu 1$
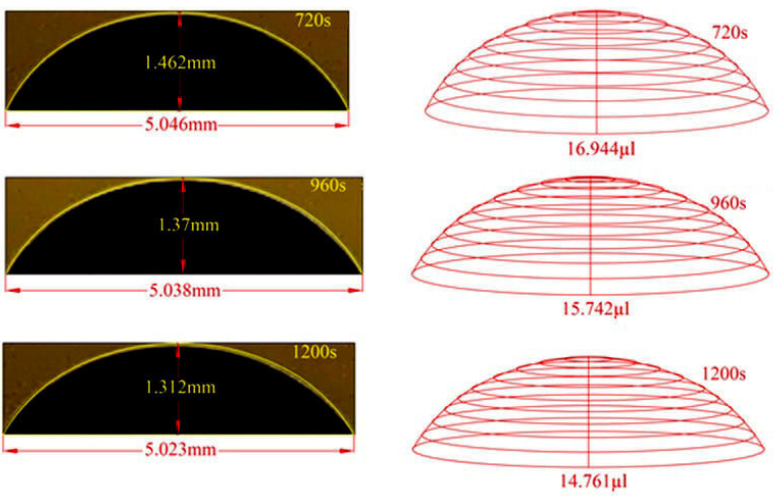

FIGURE 11. Determining the volume, height and baseline values of the drops using AUTOCAD.

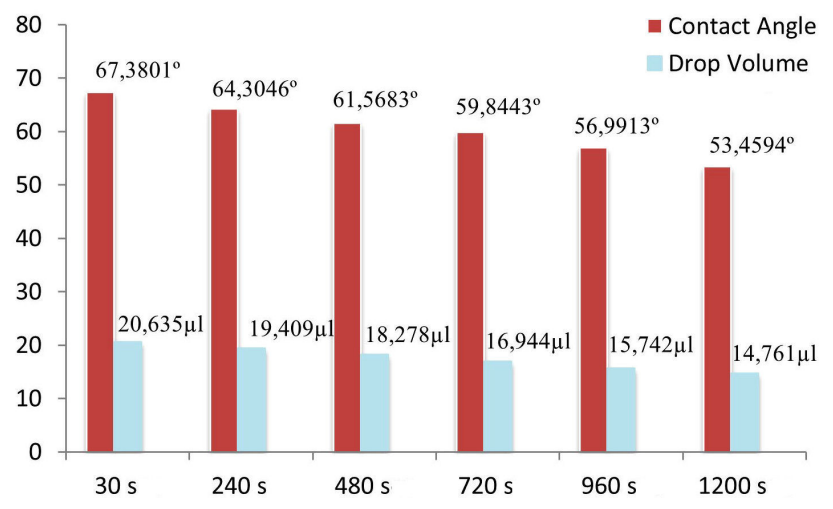

FIGURE 12. The contact angle and volume values of the drops based on waiting times.

The image of each drop obtained according to the waiting times was analyzed with AUTOCAD. and the volume, height and baseline lines were calculated. These images and values are given in Fig. 11.

In Fig. 12, average contact angle and drop volume values are calculated for each waiting time and shown in a bar graph. From close inspection of Fig. 12, it is seen that there is a decrease in the contact angle values and the volume of the drop based on the waiting times. 


\section{Conclusion}

A contact angle measurement system has been developed to be used in many industrial, educational and scientific fields. As an application of the system, measurements of the wettability of acrylic materials with a saline solution were carried out. The contact angles of the acrylic samples with a $2.4 \mathrm{M}$ saline solution were measured at different time intervals. Depending on the contact angle values, acrylic materials exhibit hydrophilic characters in the case of dropping saline on the surface. When the image of the drop shapes after each determined waiting time was analyzed, it was determined that they are symmetrical with respect to the height.
The contact angle measurement system has been created at a very affordable cost and has the flexibility to be used easily in many multidisciplinary studies. In particular, one of the most important advantages of the system is its ability to be updated and integrated with other software. Additional advantages include the ease of use, as it is straightforward for the user to conduct the experiments and analyze the extracted data, and its low cost.

In the future, it is thought to contribute to many engineering disciplines such as metallurgy and materials engineering, surface engineering, electrical electronic engineering, textile engineering, and chemical engineering.
1. J. M. Schuster, C. E. Schvezov, and M. R. Rosenberger, Influence of experimental variables on the measure of contact angle in metals using the sessile drop method. Procedia Materials Science. 8 (2015) 742, htts: //doi.org/10.1016/ j.mspro.2015.04.131

2. J. Jin, X. Wang, and M. Song, Graphene-Based Nanostructured Hybrid Materials for Conductive and Superhydrophobic Functional Coatings, J. Nanosci. Nanotechnol. 11 (2011) 7715, htts://doi.org/10.1166/jnn.2011.4730

3. T. M. Schutzius, I. S. Bayer, M. K. Tiwari, and C. M. Megaridis, Novel Fluoropolymer Blends for the Fabrication of Sprayable Multifunctional Superhydrophobic Nanostructured Composites, Ind. Eng. Chem. Res. 50 (2011) 11117, htts://doi. org/10.1021/ie200814r

4. N. Encinas, M. Pantoja, J. Abenojar, and M. A. Martínez, Control of Wettability of Polymers by Surface Roughness Modification, J. Adhes. Sci. Technol. 24 (2010) 1869, htts://doi. org/10.1163/016942410X511042

5. J.-U. Kim, et al., Effect of electrolyte in electrospun poly (vinylidene fluoride-co-hexafluoropropylene) nanofibers on dye-sensitized solar cells, Sol. Energy Mater. Sol. Cells. 93 (2009) 803, htt://doi.org/10.1016/j.solmat. 2008.09 .045

6. L. R. Freschauf, J. McLane, H. Sharma, and M. Khine, Shrinkinduced superhydrophobic and antibacterial surfaces in consumer plastics, PLOS ONE 7 (2012) e40987. htts://doi. org/10.1371/journal.pone.0040987

7. C. R. Crick, S. Ismail, J. Pratten, and I. P. Parkin, An investigation into bacterial attachment to an elastomeric superhydrophobic surface prepared via aerosol assisted deposition. Thin Solid Films 519 (2011) 3722. htts://doi.org/10.1016/j. tsf.2011.01.282

8. C.-H. Xue, J. Chen, W. Yin, S.-T. Jia, and J-Z. Ma, Superhydrophobic conductive textiles with antibacterial property by coating fibers with silver nanoparticles, Appl. Surf. Sci.. 258 (2012) 2468, htts://doi.org/10.1016/j.apsusc. 2011.10 .074

9. D. R. Bijwe et al., Complex dielectric behavior of doped polyaniline conducting polymer at microwave frequencies using time domain reflectometry, Rev. Mex. Fis.. 65 (2019) 590, htts://doi.org/10.31349/revmexfis.65.590.
10. P. Calcagnile et al., Magnetically driven floating foams for the removal of oil contaminants from water, ACS Nano. 6 (2012) 5413, htts://doi.org/10.1021/nn3012948

11. M. Karhan, Experimental investigation of wettability and evaporation for the surface of PMMA dielectric material used in high-voltage applications and outdoor electrical applications.Appl Phys. A, 127 (2021) 462.htts : / /dx . doi .org/ 10.1007/s00339-021-04630-6

12. H. Budunoglu, A. Yildirim, M.O. Guler, and M. Bayindir, Highly transparent, flexible, and thermally stable superhydrophobic ORMOSIL aerogel thin films, ACS Appl. Mater. Interface 3 (2011) 539, htts://doi.org/10.1021/ am101116b.

13. M. Lampin, R. Warocquier-Clérout, C. Legris, M. Degrange and M.F. Sigot-Luizard, Correlation between substratum roughness and wettability, cell adhesion, and cell migration.J. Biomed. Mater. Res. 36 (1998) 99, htts://doi.org/ 10.1002/(SICI) 1097-4636(199707) 36:1/99: : AID-JBM12〉3.0.CO;2-E

14. T. M. Schutzius, M. K. Tiwari, I. S. Bayer, and C. M. Megaridis, High strain sustaining, nitrile rubber based, large-area, superhydrophobic, nanostructured composite coatings, Compos. Part A Appl. Sci. Manuf. 42 (2011) 979, htts://doi.org/10. 1016/j.compositesa.2011.03.026

15. T. Verho et al., Mechanically durable superhydrophobic surfaces, Adv. Mater. 23 (2011) 673, htts://doi.org/10. $1002 / \mathrm{adma} .201003129$

16. S. Farhadi, M. Farzaneh, and S.A. Kulinich, Anti-icing performance of superhydrophobic surfaces, Appl. Surf. Sci. 257 (2011) 6264, htts://doi.org/10.1016/j.apsusc. 2011.02 .057

17. L. Ionov and A. Synytska, Self-healing superhydrophobic materials, Phys. Chem. Chem. Phys. 14 (2012) 10497, htt: //doi.org/10.1039/C2CP41377A

18. M. Karhan, M. F. Çakır, and Ö. Arslan, Investigation of the effect of roughness value on the wettability behavior under electric feld in XLPE materials used in medium and high voltage applications, Electr. Eng. 103 (2021) 3225, htts://doi. org/10.1007/s00202-021-01326-1 
19. H. Gu et al., Investigation on contact angle measurement methods and wettability transition of porous surfaces. Surf. Coat. Technol. 292 (2016) 72. htts://doi.org/10.1016/j. surfcoat.2016.03.014

20. M. Karhan, M. F. Çakır, Ö. Arslan, F. Issí, and V. Eyüpoglu, Effect of electric field on contact angle and droplet shape in XLPE dielectric materials, J. Fac. Eng. Archit. Gazi Univ.. 36 (2021) 1747, htts://doi.org/10.17341/gazimmfd. 700362

21. A.W. Neumann, R.J. Good, C.J. Hope, and M.J. Sejpal, An equation-of-state approach to determine surface tensions of low-energy solids from contact angles, Colloid Interface Sci. 49 (1974) 291, htts://doi.org/10.1016/ 0021-9797(74) 90365-8

22. F.-M. Chang, S.-J. Hong, Y.-J. Sheng, and H.-K. Tsao, High contact angle hysteresis of superhydrophobic surfaces: hy- drophobic defects, Appl. phys. lett. 95 (2009) 064102, htts : //doi.org/10.1063/1.3204006

23. R. Tadmor, Line energy and the relation between advancing, receding and Young contact angles, Langmuir. 20 (2004) 7659, htts://doi.org/10.1021/la049410h

24. C. Antonini, A. Amirfazli, and M. Marengo, Drop impact and wettability: From hydrophilic to superhydrophobic surfaces, Phys. Fluids. 24 (2012) 102104. htts://doi.org/10. $1063 / 1.4757122$

25. B. J. Ryan, and K. M. Poduska, Roughness effects on contact angle measurements, Am. J. Phys. 76 (2008) 1074. htt s: //doi.org/10.1119/1.2952446

26. S. Galindo and F. Ureña-Núñez, Enhanced surface hydrophobicity of poly (lactic acid) by $\mathrm{Co}^{60}$ gamma ray irradiation, Rev. Mex. Fis. 64 (2018) 1. https://doi.org/10.31349/ RevMexFis.64.1 